\title{
O DIREITO DA UNIÃO EUROPEIA E A DETERIORAÇÃO DEMOCRÁTICA E SOCIAL
}

\author{
EUROPEAN UNION LAW AND THE DEMOCRATIC AND SOCIAL \\ DECONSTRUCTION
}

\author{
EL DERECHO DE LA UNIÓN EUROPEA E LA DECONSTRUCCIÓN \\ DEMOCRATICA E SOCIAL
}

\section{LUIZ FELIPE BRANDÃo OSÓRIO}

http://lattes.cnpq.br/3301439900215530 / http://orcid.org/0000-0001-6058-7809 / luizfelipe.osorio@gmail.com Pós-Doutor em Direito Político e Econômico. Doutor e Mestre em Economia Política Internacional pela UFRJ. Graduação em Direito pela UFJF. Professor Adjunto de Direito e Relações Internacionais na UFRRJ.

Rio de Janeiro, RJ, Brasil.

\section{RESUMO}

Se a União Europeia representa para muitos o auge dos processos de integração regional e, consequentemente, da paz pela normatividade, na primeira crise as brumas dissipam-se, revelando o real caráter do projeto comunitário. 0 objetivo deste artigo é escancarar o processo europeu pela ferramenta da crítica ao direito. A organização internacional atinge um patamar inédito de desenvolvimento institucional e normativo, ao mesmo tempo em que se deteriora socioeconomicamente, com a desconstrução do modelo de bem-estar social. Por isso, a compreensão do fenômeno social em sua plenitude demanda um olhar pela ótica da teoria materialista do Estado. A discussão teórica envolve o desfazimento das ilusões europeias pós-Maastricht. Dessa forma, a internacionalização das relações capitalistas da era pós-fordista esgarça o modelo de bem-estar social nas sociedades europeias.

Palavras-chave: Bem-Estar Social; Direito da União Europeia; Integração Regional.

\begin{abstract}
If the European Union represents for many the process of regional integration and, consequently, peace for the sake of regulation, in the first crisis the mists were dissipated, revealing the real character of the community project. The objective of this article is to unfold the European process by the tool of critical theory of Law. The international organization reaches an unprecedented level of institutional and normative development, at the same time as it deteriorates socioeconomically, with the deconstruction of the social welfare model. For this reason, the comprehension of the social phenomenon in its fullness demands a look from the point of view of the materialist State theory. The theoretical discussion involves the undoing of post-Maastricht European illusions. In this way, the internationalization of capitalist relations in the post-Fordist era undermines the model of social welfare in European societies.
\end{abstract}

Keywords: European Union Law; Regional Integration; Welfare State.

\section{RESUMEN}

Si la Unión Europea representa para muchos el auge de los procesos de integración regional y, consecuentemente, de la paz por la normatividad, en la primera crisis las brumas se disipan, revelando el real carácter del proyecto comunitario. El objetivo de este artículo es escancar del proceso europeo por la herramienta de la crítica al derecho. La organización internacional alcanza un nivel inédito de desarrollo institucional y normativo, al mismo tiempo que se deteriora socioeconómicamente, con la deconstrucción del modelo de bienestar social. Por eso, la comprensión del fenómeno social en su plenitud demanda una mirada por la óptica de la teoría materialista del Estado. La discusión teórica implica el desajuste de las ilusiones europeas post-Maastricht. De esta forma, la internacionalización de las relaciones capitalistas de la era post-fordista saca el modelo de bienestar social en las sociedades europeas.

Palabras clave: Bienestar Social; Derecho de la Unión Europea; Integración Regional. 


\section{SUMÁRIO}

INTRODUÇAO; 1 A FORMA JURÍDICA DA UNIÃO EUROPEIA; 2 DETERIORAÇÃO SOCIAL; 3 DETERIORAÇÃO DEMOCRÁTICA; CONCLUSÃO; REFERÊNCIAS.

\section{INTRODUÇÃO}

Passados os anos de recuperação econômica e de Guerra Fria, o projeto comunitário ${ }^{1}$ de integração regional emergia da crise e do ceticismo para o apogeu. As etapas graduais de estreitamento dos laços comerciais previstas desde os primeiros documentos e discursos do pósguerra atingem um estágio outrora improvável. A euforia com a implementação do mercado comum, da União Monetária e Econômica e da área monetária única contamina todo o mundo, elevando os processos de integração regional à centralidade das discussões nas relações internacionais, como reverberações nas diversas áreas que as tangenciam, como o direito.

A ciência jurídica, por sua vez, ocupa lugar de destaque dentro da dinâmica integracionista, ressalte-se. 0 inédito desenvolvimento institucional e normativo da União Europeia deve-se ao fio jurídico, capaz de tecer unidade em um emaranhado tão heterogêneo, como as realidades sociais envolvidas. A forma jurídica será elevada à condição de objeto de análise, haja vista sua condição de elemento harmonizador da integração. Não se pode, contudo, ficar exclusivamente atrelado aos aspectos estritamente formais, os quais têm sua relevância, mas não podem ser analisados isoladamente. Falar em forma jurídica é ir além e verificar como que as práticas materiais concretas constituem as formas sociais do capitalismo, como o direito.

Desde as primeiras iniciativas de cooperação até a concretização em Maastricht, o direito foi o amálgama do processo de estreitar laços entre países díspares. Em um universo de assimetrias nacionais, a forma jurídica é que garante a homogeneidade necessária para a formação e o funcionamento de um mercado comum. Ao mesmo tempo em que viabiliza aparatos e regras

\footnotetext{
1 Importante frisar desde já a questão da nomenclatura. Para este texto o adjetivo comunitário será considerado sinônimo de europeu. Apesar da associação não ser exatamente fidedigna, em termos técnicos são equivalentes. A alcunha comunitária delineia o projeto inicial de integração, em torno das Comunidades Europeias que o constituíam, Comunidade Europeia do Carvão e do Aço (CECA), Comunidade Econômica Europeia (CEE) e Comunidade Europeia de Energia Atômica (EURATOM). Após o Tratado de Maastricht, a denominação União Europeia sobrepôs-se à Comunidade Europeia, a qual sintetizava as três supracitadas. Assim, ganhou mais força o uso do adjetivo europeu. Ainda assim, ele não corresponde exatamente ao universo de membros da organização internacional, pois há países europeus que dela não fazem parte. Sem desconsiderar a importância do rigor das classificações, para fins didáticos, fica estabelecida a equivalência de ambos os adjetivos para designar o projeto de integração regional que resultou na organização internacional União Europeia.
} 
aplicáveis a todos, a estrutura jurídica carrega, não apenas em seu conteúdo, mas também expressa em seu próprio formato, a economia política que busca consagrar. Não obstante as peculiaridades normativas que guardam o direito da União Europeia é fundamental situá-lo em sua realidade histórica e concreta para a compreensão de suas contradições imanentes. Afinal, enquanto avançam os corpos normativos e institucionais, retrocedem os índices socioeconômicos dos países comunitários.

De pronto, no contexto hodierno, cabe apontar a aporia que norteia esta pesquisa e, consequentemente, molda a juridicidade europeia (e encontra-se no cerne de sua crise vigente). $\mathrm{Na}$ trajetória do processo de integração comunitário atinge-se um patamar inédito quanto ao desenvolvimento de regras e instituições por via da cooperação interestatal e, ao mesmo tempo, neste ápice, as realidades sociais nacionais (em diferentes proporções) enfrentam graves retrocessos oriundos da desconstrução do modelo de bem-estar social, materializada nas deteriorações democráticas e sociais que se impõem.

Conforme a teoria materialista do direito e do Estado, os dois efeitos indisfarçáveis não são colaterais ou casuísticos, mas eles estão inseridos dentro de um panorama próprio, aquele que proporcionou à União Europeia se constituir como tal, um bloco econômico ímpar nas relações internacionais: o da intensificação da internacionalização das relações capitalistas de produção (que traz de roldão consequentemente a internacionalização do Estado e do direito), inerente à fase pós-fordista da historicidade do desenvolvimento capitalista. Com o auxílio desse ferramental é possível descortinar esse amplo horizonte e desvendar a realidade recôndita das formas sociais do capitalismo, como o direito. É pela formalidade que a integração econômica se constrói e se justifica.

Partindo do materialismo histórico, Pachukanis ${ }^{2}$ esboça as linhas mestras do pensamento marxista sobre a ciência jurídica e a política, traçando uma conexão profunda do direito com o capitalismo, a partir da forma mercantil, núcleo do capitalismo. Como no cerne das relações produção se encontra a troca mercantil, é fundamental entender sua correlação com a forma jurídica. 0 direito é capitalismo tanto quanto o capitalismo é direito. Pachukanis chama a atenção para o fato de que o direito não é apenas capitalista em seu conteúdo, mas, também e fundamentalmente, em sua forma. Em outras palavras, ele não se atrela ao formalismo puro, ahistórico e abstrato dos normativistas e, ao mesmo tempo, afasta-se dos sociologistas ao não focar apenas nas relações sociais que conformam o direito. Ele não rejeita o enlace formal na análise

\footnotetext{
2 PACHUKANIS, Evguiéni. Teoria Geral do Direito e Marxismo. São Paulo: Boitempo, 2017.
} 
dos fenômenos sociais e aponta para a forma legal derivada do direito realmente existente, aquele oriundo das relações materiais concretas, dadas em terreno do capitalismo ${ }^{3}$.

Nesse diapasão, parte-se do direito concreto, vinculando o abstrato ao real pela explicação da realidade das relações sociais, investigando o porquê elas tomam a forma legal. Esta é a forma particular de um tipo de relação. Em verdade, as regras sempre derivam de alguma relação concreta. O conteúdo da relação jurídica é determinado pelas relações econômicas, oriundas do modo de produção capitalista, que funciona e se reproduz pela lógica da circulação mercantil, que configura a relação de troca (de equivalentes) entre possuidores de mercadorias (como os meios de produção e a força de trabalho).

Destarte, é possível derivar os traços essenciais da circulação mercantil capitalista da forma histórica específica do direito burguês e do Estado a ele associado. Em outras palavras, tenta-se aproximar a forma do direito à forma da mercadoria. Logo, o Direito pode ser visto como uma relação social específica, que relaciona o intercâmbio de mercadorias e a personalidade jurídica. Nessa lógica, a coerção está implícita e é garantida em última instância pelo Estado, uma vez que a força tem que ser a condição geral de manutenção das relações de troca. Diferentemente do que possa parecer, o direito não é um fenômeno dado e imutável em sua essência, o qual sempre existiu desde as primeiras coletividades. Muito menos é consequência das sofisticadas elaborações teóricas dos grandes juristas. Por mais que visões tradicionalistas tentem sobrevalorizar seu objeto de estudo, atomizando-o, não há como separá-lo das relações sociais concretas, das quais ele deriva e as quais ele legitima.

As relações de troca ao se generalizarem precisam de um substrato que thes assegure unidade. 0 direito e o Estado $^{4}$ preenchem essa lacuna, uma vez que as leis que o compõem revestem-se de generalidade e abstração, sendo aplicáveis a todos, independentemente da vontade ou do lugar dentro da divisão do trabalho. Nesse sentido, a subjetividade jurídica desempenha o papel de amálgama o processo generalizado de trocas mercantis. Em outras palavras, para que estas sejam efetivas, resta imperioso que os indivíduos sejam tratados de forma isolada e atomizada. São iguais, independentemente de classe social e do lugar na divisão do trabalho (se proprietário dos meios de produção ou se trabalhador). São livres para dispor do único bem que inerentemente detêm a força de trabalho, valorada pelo salário. Portanto, o cerne do direito se funda, em última instância, nas relações de troca.

\footnotetext{
${ }^{3}$ MIÉVILLE, China. Between equal rights: a Marxist theory of international law. Leiden, Boston: Brill, 2006, p. 79.

${ }^{4}$ PEREIRA, Luiz Ismael; ERKERT, Jonathan Erik von. Uma radiografia marxista do Estado e do direito. Margem Esquerda. № 26. São Paulo: Boitempo, $1^{\circ}$ semestre de 2016, p. 147-150.
} 
Assim, com fulcro nesta trilha metodológica e com o objetivo de franquear uma discussão crítica, interdisciplinar e ampla sobre o direito da União Europeia, o texto estrutura-se em três eixos. Em um primeiro e mais importante momento, cumpre situar a engrenagem da problemática, destrinchando a forma jurídica de organização internacional e as vertentes da internacionalização das relações capitalistas. Para posteriormente, discutir as duas reverberações da constituição pósfordista do esquadro jurídico europeu, a deterioração democrática e a social. Por fim, à guisa de conclusão, as principais ideias expostas serão resumidas, de maneira a provocar e estimular debates vindouros.

Logo, o périplo que enfatiza o direito enquanto um dos elementos dissolventes do modelo de bem-estar social começa. Novos horizontes teóricos no fértil debate interdisciplinar dos processos de integração regional são imprescindíveis. Portanto, a relação entre direito e capitalismo será a ferramenta dessa tarefa. Avante!

\section{A FORMA JURÍDICA DA UNIÃO EUROPEIA}

A década de 1990 marcou um contexto de importantes transformações mundiais, e, consequentemente, regionais, uma vez que afetaram diretamente a configuração europeia ${ }^{5}$. Nessa toada, é nodal contextualizar a consolidação do que se passou a conhecer como União Europeia, após o Tratado de Maastricht, como produto do fenômeno mais amplo de intensificação da internacionalização das relações de produção, próprio do período pós-fordista do capitalismo mundial.

A nova organização social que emergia, rompendo com os parâmetros fordistas, pode ser cunhada como pós-fordista, por constituir um momento de reação, de desfazimento da correlação de outrora. Aqui, diferentemente do que ocorreu no período anterior, não há uma denominação específica ligada ao modo de organização da produção. Em verdade, a alcunha advém da negação das premissas dadas que foi a saída à crise do fordismo. Logo, o pós-fordismo é uma desconstrução e, simultaneamente, reconstrução dos parâmetros capitalistas ${ }^{6}$. Apesar dos efeitos críticos terem sido sentidos desde, pelo menos, a década de 1970, é a partir do final da Guerra Fria, na aurora da década de 1990, com a dissolução das experiências socialistas no Leste Europeu, que o ciclo pós-fordista se sedimenta. Isso porque esse período marca a consolidação e difusão pelo mundo

\footnotetext{
${ }^{5}$ ANDERSON, Perry. El nuevo viejo mundo. Madri: Ediciones Akal S.A., 2012.

${ }^{6} \mathrm{HIRSCH}$, Joachim. Fordism and Post-Fordism: the present social crisis and its consequences. IN: BONEFELD, Werner; HOLOWAY, John. Post-Fordism \& social form. A Marxist debate on the Post-Fordist State. London: Macmillan Academic and Professional LTD, 1991, p. 8-34.
} 
do novo regime de acumulação e do respectivo modo de regulação que tecerão a nova face do padrão de desenvolvimento capitalismo.

Como modelo reativo, as características embasam-se na superação das peculiaridades fordistas $^{7}$. 0 taylorismo da organização do trabalho sucumbe ao toyotismo na produção, ou seja, a racionalização do uso da força de trabalho, o crescimento da automação e da desconcentração industrial. As transformações no regime de acumulação vão nesse sentido. Pode-se cravar que, fundamentalmente, houve um deslocamento do eixo central que antes gravitava em torno do mercado interno e, agora, passa a conectar-se ao mercado internacional ${ }^{8}$. Leia-se: defesa da liberalização das regras e abertura das economias para o livre trânsito dos capitais, expandindo a sua esfera de valorização por sobre e além dos territórios nacionais.

Nessa toada, a lição fundamental é saber livrar-se da armadilha da globalização. Não é ela que marca o novo regime de acumulação. O capital, em sua essência, é internacional, é inexoravelmente expansivo, global ${ }^{9}$. 0 diferencial desse momento é a verve se que manifestou da internacionalização da produção. Por meio da liberalização dos fluxos comerciais, do fim das amarras financeiras, da livre circulação dos capitais e da introdução de novas tecnologias de comunicação e transporte criou-se uma rede ampla e flexível de possibilidades de valorização do valor, mais independentes das demandas do trabalho. 0 capitalismo é essencialmente, portanto, desde sempre, globalizado, no sentido de pressionar pela internacionalização da produção. 0 que diferencia o padrão pós-fordista de desenvolvimento são as condições estruturais dadas, de acumulação e regulação ${ }^{10}$.

O que acompanha o deslocamento do eixo de acumulação do mercado interno nacional para o espaço internacional quase sem restrições é o neoliberalismo, enquanto modo de regulação. Falar em liberalização e desregulação não significa dizer que não haja mediação política estatal, mas cabe entender o redirecionamento empreitado. 0 rearranjo impactou diretamente na atuação política estatal, carreando o desfazimento do amálgama político-ideológico que havia mantido a coesão da sociedade fordista. O Estado de segurança (Sicherheitsstaat), caracterizado pela burocratização, regulamentação, controle e normatização, foi substituído pelo Estado

\footnotetext{
${ }^{7}$ HIRSCH, Joachim; ROTH, Roland. Das neue Gesicht des Kapitalismus: vom Fordismus zum Post-fordismus. Hamburg: VSA, 1986.

${ }^{8}$ AGLIETTÁ, Michel. Zona do Euro: qual o futuro? Tradução de Christian Perret Gentil. São Paulo: Ideias \& Letras, 2013.

${ }_{9}^{9}$ MARX, Karl. O Capital. Crítica da Economia Política. Livro III: o processo global da produção capitalista. Tradução de Rubens Enderle. Edição de Friedrich Engels. São Paulo: Boitempo, 2017.

${ }^{10}$ BOYER, Robert. A Teoria da Regulação. Uma análise crítica. Tradução Renée Barata Zicman. São Paulo: Nobel, 1990.
} 
concorrencial (Wettbewerbsstaat), fomentador da competição e do livre mercado ${ }^{11}$. 0 modelo de bem-estar social (welfare) passou à desregulamentação e à precarização das condições de vida, gerando o estado de guerra econômica do livre mercado (warfare). A flexibilização das regras alterou relação entre as empresas e os Estados nacionais, a qual se reconfigura em moldes bem menos protetivos. A mitigação da intervenção nacional-estatal nas relações de produção deixou as políticas sociais e econômicas mais vulneráveis às oscilações internacionais. A postura dos governos se tornou muito mais defensiva aos efeitos do mercado do que propositiva, cabendo aos contrários apenas resistir e sem a capacidade de realizar substanciais transformações. Nesse sentido, pode-se dizer que o neoliberalismo conferiu os tons da regulação.

Diferentemente do conhecimento vulgar difundido aos quatro cantos do globo, o neoliberalismo não significa a retirado do Estado dos campos de intervenção. Criou-se uma falaciosa e ilusória oposição entre Estado e mercado que é plenamente incompatível com a dinâmica do capitalismo. O capitalismo tem no Estado a mola central de sua engrenagem. Em verdade, o que ocorre é o redirecionamento do aparato estatal para outras prioridades e áreas de atuação. Neoliberalismo não é a política do capital contra o Estado, mas a política dos capitais passando necessariamente pelo Estado. "O neoliberalismo não é a abolição da forma política estatal, mas, antes, a sua exponenciação. A mercadoria atinge, no modelo de desenvolvimento pós-fordista, instâncias maiores que aquelas nas quais atuava no modelo fordista ${ }^{12 "}$.

O Estado fordista cedeu terreno para um modelo estatal altamente voltado ao fomento dos capitais e da decorrente concorrência internacional. A desregulamentação e privatização de áreas alvos de intervenção pública limitou demasiadamente a margem de ação estatal materializada por políticas sociais ${ }^{13}$. Houve, portanto, um rearranjo das relações de classes via redirecionamento estatal para outras prioridades que não as demandas socioeconômicas.

Em outras palavras, a internacionalização do Estado faz parte de um movimento de guinada da atuação estatal para o fomento dos capitais, para a tutela de vantagens concorrenciais e para a relação com o mercado internacional, omitindo-se ou delegando competências sociais para o setor privado ou para o âmbito internacional, como na transferência de prerrogativas soberanas para as organizações internacionais (ou na celebração de tratados internacionais sobre

11 HIRSCH, Joachim. Der nationale Wettbewerbsstaat. Staat, Demokratie und Politik im globalen Kapitalismus. Berlin: Edition ID-Archiv, 1995.

${ }^{12}$ MASCARO, Alysson Leandro. Estado e Forma Política. São Paulo: Boitempo Editorial, 2013, p. 124.

${ }^{13}$ ALTVATER, Elmar. A Crise Econômica Internacional e o Desenvolvimento Sustentável. Brasil e América Latina. Vídeo-Aula 12- A Integração Europeia, a regionalização no mundo e a crise. Disciplina Tópicos Especiais do CAPES/Programa de Pós-Graduação em Políticas Públicas e Formação Humana da Universidade do Estado do Rio de Janeiro. Rio de Janeiro: Arissas Multimídia, 2013. 


\section{LDIREITO}

O DIREITO DA UNIÃO EUROPEIA E A DETERIORAÇÃO DEMOCRÁTICA E SOCIAL

LUIZ FELIPE BRANDÃO OSÓRIO

temas específicos). 0 que importa denunciar é que a internacionalização do Estado é um fenômeno que elevam a fragmentação social, visto que a capacidade de decisão das políticas socioeconômicas é cardialmente afetada.

Os Estados compensam a redução de sua margem de ação mediante a celebração de compromissos internacionais, como as alianças regionais, para tentar escapar das crises do mercado e para alcançarem posições mais vantajosas na concorrência internacional. Destarte, expandem-se consideravelmente o número de organizações e de acordos internacionais, que vão regular os mais variados assuntos e vão atuar em múltiplas áreas, conferindo ao direito internacional a crescente relevância que goza hodiernamente.

Inegavelmente $\mathrm{o}$ direito $\mathrm{e}$ as organizações internacionais expandiram-se exponencialmente no cenário mundial, passando a ocupar espaços inéditos e consolidando e incrementando as figuras e acordos já existentes. Esse aprofundamento institucional e normativo não tem uma causa específica apenas, mas requer ser inserido em um espectro mais amplo, no movimento de internacionalização do direito que veio a reboque do capitalismo pós-fordista ${ }^{14}$. 0 novo padrão de desenvolvimento do capitalismo reverberou efeitos nos constitucionalismos e nas relações jurídicas nacionais e internacionais, remodelando os eixos dos regramentos. Assim como ocorreu com a economia e a política, o direito também sentiu a alteração de paradigmas, sedimentando a nova faceta do capitalismo.

Aqui também a União Europeia pode ser pinçada como exemplo pertinente, haja vista que é o maior exponente da nova ordem capitalista. Desde as primeiras iniciativas de cooperação até a concretização estrutural em Maastricht, o direito foi o amálgama do processo de estreitar laços entre países díspares. Em um universo de heterogeneidades nacionais, a forma jurídica é que garante a homogeneidade necessária para a formação e o funcionamento de um mercado comum. Por meio de tratados e acordos internacionais, costurou-se um ordenamento jurídico autônomo e pretensamente inovador dentro da dinâmica clássica do direito internacional. Sem fugir das generalidades e liames comuns da matéria, o direito da União Europeia reluziu as mudanças de seu tempo, trazendo impactos significativos para a sociabilidade envolvida. Dentre os frutos gerados, dois são os mais destacados e vinculam-se umbilicalmente com o desenvolvimento da seara jurídica comunitária.

${ }^{14}$ OSORIO, Luiz Felipe. Um estudo crítico da União Europeia: contradições de seu desenvolvimento institucional e normativo. 2015. Tese (Programa de Pós-Graduação em Economia Política Internacional)UFRJ, Rio de Janeiro, 2015. 
São os próprios efeitos de uma integração regional moldada no pós-fordismo ${ }^{15}$, ou seja, da internacionalização do direito na nova fase do capitalismo.

Em primeiro lugar, é premente apontar o notório desacoplamento entre a formulação e a aplicação do direito. Enquanto a elaboração normativa se desliga paulatinamente dos Estados nacionais, ainda que em diferentes proporções, a sua correspondente implementação (execução/cumprimento) ainda está vinculada ao monopólio do exercício da força pelos Estados nacionais. A criação e o desenvolvimento do direito, na contemporaneidade, encontram-se cada vez mais alheados do território estatal. A emergência do ordenamento jurídico comunitário ocorreu com fulcro, fundamentalmente, em dois fatores: na força dos tratados internacionais (celebrados por representantes estatais ou tecnocratas plenipotenciários) e da jurisprudência do outrora Tribunal de Justiça das Comunidades Europeias. Moldou-se, assim, com o tempo, um espectro jurídico internacional relativamente autônomo em relação ao direito interno dos Estados.

Em segundo lugar, essa dinâmica pós-fordista fomenta um cenário de fortalecimento do Estado autoritário (quer pelo executivo, que, principalmente, pelo judiciário) e de decorrente perda de poder dos parlamentos. A racionalização imposta pela regulação neoliberal leva à necessidade constante de maior eficiência, o que carreia a orientação jurídica para uma ação política sempre punitiva e nada democrática. 0 direito da União Europeia também se apresenta como mola dessa engrenagem. O desenvolvimento institucional comunitário direcionou-se ao esvaziamento da democracia em nome de uma tecnocracia especializada, competente e eficiente, sem a necessidade de prestar contas ou de consultar a vontade popular, bem como passou a atuar pela concretização das liberdades capitalistas em detrimento das conquistas e garantias sociais. A partir da correção de rumos da década de 1990, a incorporação do ideário da economia política neoliberal manifestou-se pela via do desmonte do constitucionalismo social do pós-guerra, visando à consagração de valores econômicos, apartando a esfera econômica da social. Neste sentido, pelo aspecto jurídico, esta guinada ocorreu pela lógica do constitucionalismo neoliberal, o qual erodiu as bases sociais do pós-guerra ${ }^{16}$. Nessa toada, ao afastar-se das demandas sociais, ocorre um previsível distanciamento da população em relação à tecnocracia de Bruxelas. Quanto mais a aplicação do direito se desloca para o plano internacional, mais claramente ela se torna um assunto das burocracias governamentais e menos dos povos. Os defensores da integração chegam

\footnotetext{
15 OSORIO, Luiz Felipe Brandão. Forma política e integração regional via União Europeia. Brazilian Journal of Internacional Relations. UNESP-Marilía, 2017, Vol. 6, p. 280-305.

16 PISARELLO. Gerardo. Un Largo Termidor. La ofensiva del constitucionalismo antidemocrático. Madri: Editorial Trotta, 2011.
} 
até a reconhecer o déficit democrático, como se este problema tivesse uma solução dentro da estrutura comunitária, quando, em verdade, é ela que fomenta a não observância democrática.

Em suma, com a regulação no plano internacional, as relações de propriedade privada são vigorosamente fortalecidas em detrimentos das condições socioeconômicas gerais ${ }^{17}$. Nessa toada, a concretização da União Europeia coaduna-se em o seu entorno mundial. Em outras palavras, não foge ou afronta um milímetro da ordem estabelecida. Ao contrário, a organização internacional paradigmática é, concomitantemente com outras organizações internacionais, um sustentáculo da regulação internacional que materializa e solidifica a economia política liberal, acentuada no pósfordismo e promotora de relações burocratizadas, antidemocráticas. 0 direito da União Europeia perfila-se, portanto, no fenômeno pós-fordista, cintilando os efeitos da internacionalização das relações de produção.

A integração econômica regional via União Europeia, ou seja, pós-Maastricht, foi aventada pelos entusiastas da ascensão do neoliberalismo como exemplo concreto da pós-modernidade e da falência do Estado-nação e de seu decorrente sistema de Estados. Indubitavelmente, a organização internacional é uma ilustração notória do fenômeno da internacionalização do Estado. “Os processos regionais de integração econômica, como, sobretudo a União Europeia, são parte integrante desses processos de internacionalização do aparelho estatal ${ }^{18}$ ". O que não abre nenhuma margem para dizer que ela é a prova cabal do fim do Estado nacional. Ela não é nem nunca foi um processo voltado à formação de um Estado integral, comunitário. Ainda que o fosse, por sua constituição e por suas formas, não estaria em momento algum em contraposição ao sistema capitalista, mas, sim, como sempre, esteve em fina consonância ${ }^{19}$.

Desse modo, impõe-se entender a União Europeia pela forma em que se manifesta para que não se incorra em confusões e equívocos. A integração econômica comunitária, que se consolidou e se fortificou em um bloco econômico, não resultou em um Estado, nem tem esse objetivo como horizonte, ou qualquer outra reminiscência próxima à condição estatal. A construção da União Europeia ocorreu pela via de organização internacional, a qual se inseriu e acompanhou o movimento da internacionalização do Estado, próprio do pós-fordismo. Produto dessa fase do sistema de Estados no capitalismo, ela precisa ser delineada em sua real concretude. A forma jurídica da União Europeia é um elo de relações econômicas, cujo elemento unificador é

\footnotetext{
17 PACHUKANIS, Evguiéni. Teoria Geral do Direito e Marxismo. São Paulo: Boitempo, 2017.

18 HIRSCH, Joachim. Teoria Materialista do Estado: processos de transformação do sistema capitalista de Estados. Rio de Janeiro: Editora Revan, 2010, p. 225.

19 PANITCH, Leo; GINDIN, Sam e AQUANNO, Scott. American Empire and the relative autonomy of European capitalism. In: Competition \& Change. Vol. 19 (2), 2015, p. 113-128.
} 
o direito, o amálgama de estruturas tão díspares. Disso reluzem as reverberações resplandecentes, inerentes ao fenômeno da internacionalização do direito no capitalismo pós-fordista, o que se convenciona chamar aqui de: deterioração social e a democrática.

Por meio do alargamento institucional e normativo, por cima e fora dos debates nacionais, via organização internacional, encetou-se o desmantelamento das barreiras democráticas e dos modelos sociais na Europa. A partir da correção de rumos da década de 1990, a incorporação do ideário da economia política neoliberal manifestou-se pela via do desmonte do constitucionalismo social do pós-guerra, visando à consagração de valores econômicos, apartando a esfera econômica da social, o qual erodiu as bases sociais do pós-guerra. 0 novo pacto social a ser fundado pela estrutura jurídica comunitária é revestido pela modernização neoliberal, que mascara a deterioração social e a democrática, ambas em potencializadas desde a inflexão de Maastricht, a ser agora denunciadas.

\section{DETERIORAÇÃO SOCIAL}

O que se cunha por precarização das condições sociais envolve diretamente a perda de direitos e garantias fundamentais. Não que se adote um viés normativista nesta abordagem. Ao contrário, a ideia é mostrar que a formalidade jurídica não a âncora de salvação de nenhum cidadão. Pela teoria da forma mercantil, não, aliás, o socialismo jurídico ${ }^{20}$ não é uma opção viável. Não é pelo aumento da legalidade que se transforma ou supera o capitalismo ${ }^{21}$. No caso europeu, em voga, a desconstituição de garantias ocorre não apenas na interpretação de seu conteúdo, mas, principalmente, pelos mesmos mecanismos formais, que sinalizam, para o pensamento normativista, evidência de avanço na integração ${ }^{22}$. 0 direito da União Europeia é tão propalado justamente por ter maior operacionalidade via atuação legiferante do órgão jurisdicional, efeito direto das normas e primazia, constituindo um ramo autônomo dentro do direito internacional. Os três instrumentos citados alavancam a peculiaridade do ordenamento jurídico comunitário. Há que se pontuar que eles não significam nada além de facilitadores para imposição de decisões e

\footnotetext{
${ }^{20}$ NAVES, Márcio Bilharinho. Prefácio ao livro O Socialismo Jurídico. IN: ENGELS, Friedrich; KAUTSKY, Karl. O Socialismo Jurídico. São Paulo: Boitempo, 2012, pp. 9-16.

21 PACHUKANIS, Evguiéni. Teoria Geral do Direito e Marxismo. São Paulo: Boitempo, 2017; MASCARO, Alysson Leandro. Estado e Forma Política. São Paulo: Boitempo Editorial, 2013.

22 ALDECOA LUZÁRRAGA, Francisco; GUINEA LLORENTE, Mercedes. La Europa que viene: El Tratado de Lisboa. Versiones consolidadas del Tratado de la Unión Europea y del Tratado de funcionamento de la Unión Europea. Madri: Marcial Pons, 2008; DINH, Nguyen Quoc, PELLET, Alain e DAILLIER, Patrick. Direito Internacional Público (2 ed.). Lisboa, Calouste Gulbenkian, 2003; MANGAS MARTíN, A; LIÑÁN NOGUERAS, D. J. Instituciones y Derecho de la Unión Europea. 6. ed. Madrid: Tecnos, 2005.
} 
regramentos que ceifam direitos e garantias do indivíduo, potencializando a crise social que 0 continente europeu se encontra. Uma vez que menos direitos e garantias sociais traduz uma condição deteriorada no convívio social e na barganha no mercado de trabalho. Logo, verifiquemos a mecânica jurídica que contribui para solapar o bem-estar social.

Em primeiro lugar, o papel legislador da Corte comunitária, ratificado pelo instituto jurídico do reenvio prejudicial. Em segundo lugar, o efeito direto do direito secundário, visto que pode ser invocado perante os tribunais nacionais, sem a necessidade de passar pelo procedimento de incorporação dos tratados internacionais. Por fim, em terceiro lugar, a primazia em relação às esferas nacionais que goza o direito derivado.

No tocante à função pretoriana, é possível comparar sua atuação às cortes da tradição do common law, as quais possuem o poder legislativo como uma das funções precípuas, diferentemente da lógica romano-germânica, aquela que rege a maior parte dos países europeus continentais: “À semelhança das cortes soberanas do Antigo Regime ou dos tribunais supremos de common law, legisla para o futuro por disposições gerais, que afeta a todos, como mesmo uma lei ${ }^{23 "}$. Em outras palavras, as sentenças jurisdicionais podem ser gerais e abstratas, com efeitos erga omnes, como as leis, e em virtude disso, são a elas equiparáveis. Em outras palavras, a Corte teria nas mãos, além dos Estados-membros, o poder constituinte do direito comunitário. Logo, o Tribunal de Justiça da União Europeia possui, na prática, junto com os Estados-membros, a competência das competências, ao formular as normas que guiam o funcionamento do arcabouço jurídico. Isso acontece por meio dos julgados e pareceres, ou mesmo via reenvio prejudicial. Esse instrumento processual pavimenta um caminho para o esvaziamento do direito nacional dos Estados em nome das imposições do tribunal comunitário.

Quanto ao efeito direto do direito secundário, cabe ressaltar que ele afeta diretamente a esfera de direitos do indivíduo, sem passar por nenhum procedimento de consulta. Doutrina e jurisprudência preferiram, ao invés de convocar o poder constituinte por representantes populares, atribuir efeito direto para a juridicidade secundária garantir sua operacionalidade normativa. Nesse diapasão, é imperioso ressaltar que esta festejada característica (efeito direto do direito secundário) não foi conferida pelo direito interno dos Estados ou mesmo pelo direito primário, mas pela interpretação e aplicação dadas pela jurisprudência, que no caso concreto se

23 PISARELLO. Gerardo. Un Largo Termidor. La ofensiva del constitucionalismo antidemocrático. Madri: Editorial Trotta, 2011, p. 183. 
relacionada com o julgado Van Gend en Loos, prolatado pelo Tribunal de Justiça da União Europeia $^{24}$.

O efeito direto é complementado pela primazia da legislação comunitária sobre a nacional. Os limites da primazia do direito comunitário são, entretanto, uma questão controversa, haja vista a fragilidade jurídica da fonte que a consagra. A depender da interpretação, pode ganhar contornos distintos ${ }^{25}$. Entusiastas da supranacionalidade defendem a imperiosidade do direito regional, que sem preponderância não teria razão de existir. Esta visão acaba instituindo a primazia como regra a ser aplicada pelo juiz nacional, sem margem de discricionariedade, bem como dotada de alcance absoluto, podendo inclusive a norma comunitária revogar ou suspender os efeitos de norma constitucional que lhe seja contrária. Ainda assim, o conflito entre cortes nacionais e a europeia não possui um padrão de resolução e deverá sempre depender do caso concreto ou, mais especificamente, da matéria tratada. Os tribunais nacionais reconhecem a validade da primazia e do efeito direto, mas como elementos próprios do sistema de delegação de competências entre Estados membros e organização internacional, relação que, por ser regida por princípios como os da especialidade e subsidiariedade, não afrontaria a soberania estatal, mas, sim, desenvolveria com ela, em teoria, uma interação de respeito e coordenação.

A tríade citada (efeito direto, primazia e reenvio prejudicial) configura a articulação específica que permite a desconstrução de direitos por meio de instrumentos jurídicos. Por trás das aparentes inovações formais está a velha dinâmica capitalista, moldada nesse ínterim pelo padrão pós-fordista. Logo, a economia política segue seu rumo.

Mesmo na integração econômica, na liberdade do espaço comum, como as economias nacionais estão abertas ao mercado internacional, há a disputa entre os Estados, sempre na tentativa de oferecer melhores condições para o capital estrangeiro, fomentando a internacionalização. Essa concorrência, por si só, já leva a um cenário preocupante. 0 que atrai os investimentos são baixos custos e elevada rentabilidade. Nesse sentido, o preço da mão de obra conta como variável importante a ser considerada. Sua diminuição implica, inexoravelmente, na desmobilização dos arranjos sociais internos. Por isso, dentro da lógica da modernização neoliberal, estava incutido o desmonte do modelo de bem-estar social, o qual elevava demasiadamente o custo do trabalho do ponto de vista dos capitais. Há, por conseguinte, a pressão

\footnotetext{
${ }^{24}$ MANGAS MARTÍN, A; LIÑÁN NOGUERAS, D. J. Instituciones y Derecho de la Unión Europea. 6. ed. Madrid: Tecnos, 2005.

${ }^{25}$ BELLAMY, Richard; CASTIGLIONE, Dario. O Déficit Democrático da Europa e o Problema Constitucional. IN: COSTA, Piero; ZOLO, Danilo. O Estado de Direito: história, teoria, crítica. São Paulo: Martins Fontes, 2006, p. 630.
} 
dos capitais internos e internacionais pela flexibilização das garantias e direitos trabalhistas, bem como pela isenção fiscal e tributária, ou seja, para o redirecionamento do Estado e para a internacionalização de sua estrutura jurídica, guinada que acirra as tensões sociais.

Entre si, os Estados passam a atuar no sentido de uma sistemática concorrência para oferecer aos capitais melhores condições para o investimento, disputando a sua internalização. Tal processo leva à fragilização das condições sociais internas, o que gera novos e específicos conflitos, demandas e lutas ${ }^{26}$.

Essa dinâmica reforça a dependência do setor externo nacional do cenário pós-fordista. A regionalização do tratamento e do controle de temas econômicos, ao mesmo tempo em que incrementa o arcabouço formal comunitário, subordina as economias nacionais às variações do mercado, minando a capacidade de elaboração de políticas públicas socialmente efetivas. Em outras palavras, com a materialização das premissas neoliberais dos países europeus na correção de rumos de Maastricht, não apenas se iniciou o desmonte do arranjo social interno, mas, ao internacionalizar certas competências estatais, tornou o poder público ainda mais vulnerável aos capitais internacionais, decepando sua capacidade de fomentar políticas sociais e econômicas substanciais que atenuem os efeitos críticos das oscilações mercadológicas. Disso decorrem conflitos, demandas e lutas, causados pela fragilização das conquistas sociais.

Nesse diapasão, identifica-se que uma das formas encontradas de reverter as conquistas sociais sem grande resistência interna é a constituição da organicidade internacional. A arquitetura da União Europeia obedece à racionalidade econômica condensada em suas estruturas. Seu avanço normativo é referente à liberdade de bens, serviços, capitais e pessoas ${ }^{27}$ (refere-se ao turismo, ao trânsito interno e à circulação de mão de obra qualificada, e não ao trabalho ou à migração oriunda da periferia), tocando marginalmente à questão da liberdade de trabalho e menos ainda à institucionalização do conflito entre capital e trabalho, deixando os assuntos a cargo das regulações nacionais. Busca-se entender a economia como uma área descolada da social, cuja racionalidade seria automática no alcance da eficiência. Esse desacoplamento dos setores induz à priorização das premissas liberais em detrimento dos valores do trabalho e do bem-estar, prevalecendo a lógica da integração negativa ${ }^{28}$.

\footnotetext{
${ }^{26}$ MASCARO, Alysson Leandro. Estado e Forma Política. São Paulo: Boitempo Editorial, 2013, p. 105.

${ }^{27}$ AVELÃS NUNES. Crise do Capitalismo, Crise da Europa. Parte II. Revista Jurídica Unicuritiba. Vol. 1. $\mathrm{n}^{\circ}$ 34, Curitiba, 2014b, p. 5-24.

${ }^{28}$ ALTVATER, Elmar. A Crise Econômica Internacional e o Desenvolvimento Sustentável. Brasil e América Latina. Vídeo-Aula 12- A Integração Europeia, a regionalização no mundo e a crise. Disciplina Tópicos Especiais do CAPES/Programa de Pós-Graduação em Políticas Públicas e Formação Humana da Universidade do Estado do Rio de Janeiro. Rio de Janeiro: Arissas Multimídia, 2013.
} 
O raciocínio economicista inverte a escala de prioridades do Estado, acirra ainda mais as disparidades existentes entre os países, cujos panoramas sociais são consideravelmente distintos. Para que uma área de liberdades de capitais, de mercadorias, de serviços e de pessoas funcione é preciso que o contexto estrutural e social daquele espaço seja homogêneo. Se antes da década de 1990, com menos membros, já era difícil encontrar uniformidade, após as ondas de adesões pós-Maastricht, a tarefa tornou-se intangível. 0 descompasso é evidente quando se compara as legislações trabalhistas de Alemanha e França em relação àquelas dos governos recémincorporados, cuja transição do socialismo para a democracia liberal foi brusca, com fraturas internas significativas, como as nações bálticas ${ }^{29}$. Naturalmente isto gera assimetrias na interface entre capital e trabalho, concedendo margem para as empresas explorarem as diferenças, gerando dumping social, tendo em vista sua liberdade de atuação, o que acirra conflitos salariais e ascende o confronto dos trabalhadores entre si por meio de sentimentos nacionalistas xenófobos no tocante ao trabalhador estrangeiro, minando a solidariedade social ${ }^{30}$.

Ao invés de corrigir a situação, a Corte comunitária, na intepretação e na aplicação das normas regionais, corrobora e aprofunda a lógica tecnicista, adotando uma postura muito mais favorável aos interesses empresariais que aos trabalhistas. Exemplos deste posicionamento são ilustrados por quatro julgados proferidos (ainda em 2008), nos quais houve uma legitimação do dumping social no continente. Muitos trabalhadores tiveram suas garantias, consagradas em convenções coletivas e legislações pertinentes, violadas em nome de direitos econômicos. Neste sentido, entendeu-se a greve como um instrumento que emperra e obstaculiza a liberdade empresarial, como ocorreu nos casos que envolveram a embarcação Viking Line ${ }^{31}$, a sociedade letã

29 PISARELLO. Gerardo. Un Largo Termidor. La ofensiva del constitucionalismo antidemocrático. Madri: Editorial Trotta, 2011, p. 183.

30 DOUZINAS, Costas. Class bites back in European Union Euro. Disponível em: $<$ http://criticallegalthinking.com/2009/04/03/class-bites-back-in-the-european-union/>. Acesso em: 15 jan. 2013.

${ }^{31}$ No acórdão C-438/05 de 2008, a Federação Internacional dos Trabalhadores dos Transportes e o Sindicato Finlandês dos Trabalhadores Marítimos ameaçaram iniciar um movimento de greve para protestar contra o projeto da Viking Line de mudar o pavilhão finlandês de um dos seus navios para registrá-lo na Estônia, bem como substituir sua tripulação por trabalhadores estonianos, de forma a poder pagar salários inferiores em relação aos finlandeses. O Tribunal de Justiça exarou decisão no sentido de que a ameaça de greve para forçar um empregador a cumprir uma convenção coletiva poderia, neste caso, impor restrições à liberdade de estabelecimento, logo, sendo indeferido o direito trabalhista. 
Laval $^{32}$ e o decreto Rüffert ${ }^{33}$ e no caso Luxemburgo ${ }^{34}$. Em todos foi legalizada a precarização salarial, afetando diretamente o direito de indivíduos e de categorias sindicais, sobrepondo-se mesmo às legislações nacionais, desprezando o direito trabalhista em cada Estado-membro. Em verdade, o que se pode extrair da jurisprudência é a postura do colegiado de reconhecer nas garantias trabalhistas e sociais e nas organizações sindicais barreiras à implementação das liberdades negociais.

Essa visão economicista do Tribunal de Justiça da União Europeia coaduna-se com a interpretação de justiça social dada hodiernamente ao ordenamento jurídico comunitário. É uma noção afinada com um modelo calcado na eficiência e na percepção de que o mercado deve decidir quanto à alocação de recursos e à regulação econômica, sem a intervenção estatal, em meio ao conflito permanente entre capital e trabalho. Nesse sentido, são empreendidas medidas em direção ao redirecionamento do Estado, mediante um modelo privatizador que contribuiu para debilitar o papel dos serviços públicos e para precarizar o setor laboral. A conceituação de que quanto menos Estado, melhor, impacta diretamente no decréscimo dos salários e do poder de compra do trabalhador, no desmantelamento do aparato estatal e dos serviços públicos e na visão dos direitos sociais enquanto barreiras ao progresso, transformando-os em assistencialismo de exceção. Destarte, o arranjo colaborou para a desconstrução do modelo de bem-estar social, bem como afetou diretamente aos direitos trabalhistas e às conquistas sociais, agudizando o processo de deterioração social e de concentração de renda, pelo que passam as sociedades locais, sobretudo as periféricas. É a política centrada na redução dos custos unitários da força de trabalho, isto é, no reforço da exploração dos trabalhadores.

\footnotetext{
32 No acórdão C-341/05 de 2008, a Laval, empresa letã, levava trabalhadores para exercer seu ofício na Suécia, mas aplicando a legislação letã, que viabiliza o pagamento de salários bem inferiores àqueles estipulados em convenções coletivas suecas. Incomodados com a disparidade, os sindicatos suecos entraram em greve e bloquearam a obra na cidade de Vaxholm. O Tribunal de Justiça prolatou sentença no sentido de declarar a ilegalidade de qualquer greve organizada pelos sindicatos para obtenção de condições mais favoráveis.

33 O acórdão C-346/06 de 2008, sobre o processo Rüffert, trata de uma empresa alemã chamada Rüffert que venceu um certame público promovido pelo Estado Federado da Baixa Saxônia para a realização de serviços de construção em estabelecimento prisional. Para a realização das obras, ela contratou uma empresa polonesa, que pagou aos trabalhadores valores relativos a 47 \% do salário mínimo previsto na convenção coletiva regional. Em virtude desta violação, o governo da Baixa Saxônia rescindiu o contrato licitatório. 0 Tribunal de Justiça considerou, todavia, que a legislação alemã localmente, a qual obriga os contratantes da construção civil a respeitar as convenções coletivas, não é compatível com a diretiva comunitária relativa ao deslocamento de trabalhadores, e, portanto, não poderia ser aplicada, validando a situação em tela.

${ }^{34}$ No acórdão C-319/06 de 2008, o Tribunal de Justiça deferiu o pedido da Comissão Europeia ao decidir que Luxemburgo tinha exagerado na aplicação da diretiva relativa à alocação de trabalhadores. 0 país estava impondo muitas exigências às empresas nacionais na observância dos direitos trabalhistas consagrados internamente, como os períodos máximos de trabalho e períodos mínimos de descanso, indexação automática dos salários e respeito às convenções coletivas.
} 
Dessa forma, tendo em vista o que foi narrado, há que se apontar a tendência da regionalização da estrutura jurídica, por sobre a política nacional, leva a um cenário altamente desfavorável ao trabalho e atinente aos interesses capitalistas. Na Europa do Capital ${ }^{35}$, a supranacionalização das instituições comunitárias serve apenas para garantir a realização dos direitos e das liberdades do capital, mas não serve para garantir o direito dos trabalhadores. Com essa proposta de integração, a perspectiva é que as conquistas sociais sejam deterioradas e os lucros do capital financeiro permaneçam crescendo em detrimento do bem-estar local. A cena atual alarma a ruína das conquistas não apenas sociais e trabalhistas, mas democráticas como um todo, à medida que se cristaliza o poder dos grandes conglomerados financeiros na condução da integração, alterando sua configuração e transformando as populações nacionais em reféns da política regional. Assim, é possível desfazer a ilusão e compreender a contradição do desenvolvimento normativo.

\section{DETERIORAÇÃO DEMOCRÁTICA}

Discutir sobre a ausência de vinculação aos princípios democráticos é indubitavelmente uma tarefa polêmica. Isto porque o debate remete a dois aspectos fundamentais: ao conceito de democracia e à natureza político-jurídica da União Europeia.

Por ora, não cabem maiores explanações sobre definições conceituais. 0 importante ressaltar é que, dentro da respeitada doutrina ${ }^{36}$ (tanto da ciência política quanto do direito), dois aspectos da democracia são apontados em uma relação de direta interface. A verve material e o prisma procedimental. Materialmente significa que o conteúdo das normas precisa estar conforme os consagrados princípios democráticos, regidos pelo crivo popular, cujo núcleo é frequentemente

\footnotetext{
${ }^{35}$ AVELÃS NUNES, António José. Crise do Capitalismo, Crise da Europa. Parte I. Revista Jurídica Unicuritiba. Vol 4. $\mathrm{N}^{\circ} 33$, Curitiba, 2014a, p. 5-22.

36 ALDECOA LUZÁRRAGA, Francisco; GUINEA LLORENTE, Mercedes. La Europa que viene: El Tratado de Lisboa. Versiones consolidadas del Tratado de la Unión Europea y del Tratado de funcionamento de la Unión Europea. Madri: Marcial Pons, 2008; AVELÃS NUNES, António José. Crise do Capitalismo, Crise da Europa. Parte I. Revista Jurídica Unicuritiba. Vol 4. N ${ }^{\circ}$ 33, Curitiba, 2014a, p. 5-22; BELLAMY, Richard; CASTIGLIONE, Dario. O Déficit Democrático da Europa e o Problema Constitucional. IN: COSTA, Piero; ZOLO, Danilo. O Estado de Direito: história, teoria, crítica. São Paulo: Martins Fontes, 2006, p. 611-648; DINH, Nguyen Quoc, PELLET, Alain e DAILLIER, Patrick. Direito Internacional Público (2 ed.). Lisboa, Calouste Gulbenkian, 2003; DOUZINAS, Costas. The End of Politics (2): Europe. Disponível em: <http://criticallegalthinking.com/2010/11/23/the-end-of-politics-2-europe/>. Acesso em: 15 maio 2014; MANGAS MARTÍN, A.; LIÑÁN NOGUERAS, D. J. Instituciones y Derecho de la Unión Europea. 6. ed. Madrid: Tecnos, 2005; HIRSCH, Joachim. Teoria Materialista do Estado: processos de transformação do sistema capitalista de Estados. Rio de Janeiro: Editora Revan, 2010; PISARELLO. Gerardo. Un Largo Termidor. La ofensiva del constitucionalismo antidemocrático. Madri: Editorial Trotta, 2011.
} 
expresso nos documentos constitucionais ou em tratados constituintes. Procedimentalmente abrange o respeito ao devido processo legal na feitura e execução do conteúdo normativo.

A discussão da classificação do modelo europeu traz apontamentos relevantes. Como é, todavia, sui generis, no sentido de possuir peculiaridades que a distinguem de suas congêneres, sobretudo, no que tange à produção de efeitos normativos diretos na esfera do indivíduo, nacional do Estado parte, é consenso na doutrina ${ }^{37}$ que o cumprimento dos preceitos democráticos é imperioso, sob pena de se tornar uma organização arbitrária de poder, podendo vir a violar direitos humanos consagrados. Malgrado o apelo doutrinário, não se verifica nos tratados reformadores o incremento democrático. Mesmo as mudanças trazidas pelos Tratados de Lisboa não alteram este panorama, cuja configuração se cristalizou mediante a guinada europeia ao pós-fordismo, formalizada pelo Tratado de Maastricht e o aprofundamento da cooperação monetária.

Há, definitivamente e em pleno vapor, o fortalecimento de instituições regionais executivas, as quais não possuem relação direta e constante com as populações que tutelam. Verifica-se, com isso, um esvaziamento das caixas de ressonância popular das nações em favor de decisões tomadas por tecnocratas nacionais em âmbito regional. Quanto mais a aplicação do direito se desloca para o plano internacional, mais claramente ela se torna um assunto das burocracias governamentais e menos dos povos. Nesse sentido, emerge a contradição das formas, pois o incremento orgânico, ao invés de êxito, traz preocupações crescentes, relacionadas à vinculação do indivíduo a órgãos arbitrários na imposição de suas medidas.

O temor do avanço antidemocrático já parece concretizado, uma vez que esta arbitrariedade é inerente à forma europeia constituída. Os moldes e o funcionamento da arquitetura comunitária carecem necessariamente de premissas democráticas, sendo que a forma corrobora o conteúdo político-econômico liberal. Déficit democrático torna-se um eufemismo quando contraposto à prosaica realidade. "Este eufemismo esconde, contudo, a verdade. A União Europeia não tem um déficit, mas uma ausência total de democracia ${ }^{38 " . ~ P a r a ~ i l u s t r a r ~ e s s a ~ a u s e ̂ n c i a ~}$ é possível listar, pelo menos, três assimetrias formais, que maculam quaisquer tentativas de atribuir um potencial coeficiente democrático à organização. Elas envolvem: a) o método de constitucionalização via tratados internacionais, que não corresponde aos procedimentos políticojurídicos típicos do Estado de Direito e dos regimes democráticos, devido à ausência do poder

\footnotetext{
37 ALDECOA LUZÁRRAGA, Francisco; GUINEA LLORENTE, Mercedes. La Europa que viene: El Tratado de Lisboa. Versiones consolidadas del Tratado de la Unión Europea y del Tratado de funcionamento de la Unión Europea. Madri: Marcial Pons, 2008.

38 DOUZINAS, Costas. The End of Politics (2): Europe. Disponível em: <http://criticallegalthinking.com/2010/11/23/the-end-of-politics-2-europe/>. Acesso em: 15 maio 2014
} 
constituinte originário popular; b) o deslocamento dos poderes decisórios do âmbito nacional para o regional, o que relativiza a legitimidade popular, bem como não estabelece limites definidos para suas competências; c) por fim, a incapacidade de controle dos cidadãos tanto a priori como a posteriori sobre as instituições e a falta de transparência de seu funcionamento.

No que se refere à constitucionalização dos tratados internacionais, cabem maiores esclarecimentos. É fundamental notar que quem eleva as convenções ao status hierárquico maior é a jurisprudência de uma única corte, o Tribunal de Justiça da União Europeia. Em outras palavras, é o órgão jurisdicional próprio que cria, ao longo da vigência dos tratados (o que não constava literalmente no momento de ratificação dos membros), uma ordem jurídica relativamente autônoma e a organiza. Neste ímpeto, estabelece a constitucionalização do direito primário europeu, de cunho eminentemente econômico (tendo em vista as matérias que regula). Além disto, o tribunal sub-roga-se na posição de modelador do sistema, reivindicando para si a competência das competências, prerrogativa exercida pelos Estados no momento da celebração pactual. Desta forma, atribui características ao direito comunitário, como a tríade supracitada (efeito direto, primazia sobre as disposições nacionais e reenvio prejudicial), que the conferem a capacidade de dizer quando e como se aplicam as normas regionais. Todo este processo ocorre à revelia popular, interferindo diretamente na soberania estatal e na organização constitucional legitimada pelos nacionais dos Estados-membros. São tratados interestatais que reverberam diretamente na esfera de direitos do indivíduo, podendo subjugar a ordem nacional, sem previsão expressa para esta tarefa ${ }^{39}$.

A construção de um sistema normativo complementar vincula-se ao deslocamento dos poderes nacionais para o âmbito regional, a segunda assimetria formal. As competências exclusivas transferidas são majoritariamente relativas a assuntos econômicos, sem uma clara delimitação pelos entes delegatórios. Afasta-se, assim, a influência dos centros de poder nacionais, sobretudo dos parlamentos. Nesse esquema, as instituições regionais, que não respeitam princípios básicos (como o da separação de poderes), são encorpadas normativamente. É uma organização internacional que afeta diretamente o rol de direitos das populações, sem que tenha respaldo democrático para fazê-lo. A desproporção desta anacronia é evidente, quando se aproxima o enfoque para a estrutura orgânica via sua constituição e seu funcionamento. 0 emaranhado de disposições comunitárias é imposto aos Estados membros, elaborado pela Comissão Europeia,

${ }^{39}$ BELLAMY, Richard; CASTIGLIONE, Dario. O Déficit Democrático da Europa e o Problema Constitucional. IN: COSTA, Piero; ZOLO, Danilo. O Estado de Direito: história, teoria, crítica. São Paulo: Martins Fontes, 2006, p. 639. 
órgão executivo, sem maiores discussões pelo Parlamento (esvaziado) e sem o crivo democrático das instâncias internas ${ }^{40}$.

A segunda incompatibilidade relaciona-se com a terceira incongruência supramencionada. Há um círculo vicioso conveniente às tendências antidemocráticas da União Europeia. Como não há nem incentivo, muito menos participação efetiva do cidadão nos rumos comunitários, a desídia impera. Logo, as eleições parlamentares europeias são mera formalidade, pois são cada vez mais esvaziadas, agregando forças partidárias sem grande coesão intelectual e reunindo quadros periféricos em comparação com o processo político interno. Neste diapasão, a tentativa de reforma institucional ventilada pelos Tratados de Lisboa, ao contrário do que anunciou, ao modificar algumas regras e composições, reforçou a lógica antidemocrática, mantendo o esvaziamento dos foros de representação popular em favor de órgãos executivos, de decisões céleres e sem grandes debates. As principais transformações normativas foram realizadas pelos Estados, quando celebraram os tratados constitutivos, momento em que a influência do cidadão é quase nula. O controle social posterior também se demonstra inexpressivo pela falta de mobilizações críticas, em que pese seu recente incremento. Malgrado as alterações pontuais, como a iniciativa popular e o direito de petição, funcionam os instrumentos como remédios aparentes que, em verdade, ocasionam mudanças conjunturais para que a estrutura seja mantida. Tenta-se viabilizar a transparência pela ampla forma de divulgação e publicações que a União possui, sempre com a retórica do diálogo aberto e regular com a sociedade civil e representações organizadas. Em verdade, a propagada neutralidade e tecnicidade, dadas ao tratamento de questões específicas em foros supranacionais, reverberam o exato oposto dos efeitos que anunciam $^{41}$.

Tendo em vista estas três assimetrias que ratificam a carência democrática da União Europeia, é possível apontar os indícios da deterioração democrática que reverbera do bloco, afetando as sociedades nacionais. Os órgãos comunitários, independentes dos governos nacionais, exercem suas competências à margem de balizas democráticas, direcionando as decisões aos interesses representados pelas cúpulas governistas. Fica cada vez mais evidente a influência do capital na condução da integração econômica europeia. Desde os primórdios, os anseios financistas foram levados em conta no vetor da formação do mercado comum livre. A transferência de

40 DOUZINAS, Costas. The End of Politics (2): Europe. Disponível em: <http://criticallegalthinking.com/2010/11/23/the-end-of-politics-2-europe/>. Acesso em: 15 maio 2014 ${ }^{41}$ AVELÃS NUNES, António José. Crise do Capitalismo, Crise da Europa. Parte I. Revista Jurídica Unicuritiba. Vol 4. $\mathrm{N}^{\circ} 33$, Curitiba, 2014a, p. 5-22. 
ISSN 1981-3694

(DOI): $10.5902 / 1981369429158$

competências estatais quanto ao viés econômico foi gradativa até culminar na aceleração desse processo de delegação.

Nesse diapasão, notória é a influência que os capitais exercem sobre o arcabouço comunitário. Neoliberalismo e autoritarismo evidenciam que são faces do mesmo processo. Esse fenômeno é mascarado pelo debate aparente sobre a organização política do bloco, forjando na inócua discussão sobre a natureza da institucionalidade europeia o real caráter da condução comunitária, que se esconde nos moldes formais hodiernos. Em verdade, o discurso europeísta democrático é utilizado quando interessa aos desígnios capitalistas conduzir a opinião pública ao respaldo das medidas tomadas. Quando a consulta popular pode atrapalhar, ela, e até toda a organicidade, é ignorada ou desconsiderada, haja vista a pouca relevância decisória que possui. Esse contexto avesso às premissas democráticas favorece (e acelera) a violação de direitos e a reversão do modelo de bem-estar social, ocasionando, em inter-relação com o abalo democrático, um cenário de deterioração social.

\section{CONCLUSÃO}

Diante do que foi dissertado ao longo do texto, quando se analisa a economia política amalgamada na forma jurídica, chega-se a algumas considerações quanto ao processo que resultou na União Europeia e em seu direito peculiar.

Em primeiro lugar, é preciso ter em mente que a forma que constitui a União Europeia é datada do contexto da década de 1990. Em outras palavras, o bloco econômico de estreitos laços de interdependência é produto da guinada de Maastricht. Nesse sentido, buscar as raízes da situação crítica vivida pelo bloco é remontar ao relançamento da integração. Nele evidenciou-se, portanto, que a criação da organização internacional União Europeia (via Tratado de Maastricht), a qual incorporou e materializou as transformações próprias da era pós-fordista do capitalismo. Seguiu as reverberações do padrão de desenvolvimento ao acompanhar o deslocamento do regime de acumulação do âmbito interno ao internacional e ao cristalizar o modo de regulação neoliberal. Com a concretização dessa engrenagem, que se diferenciou do momento anterior, fordista, a integração econômica europeia rompeu paradigmas, tanto que ganhou alcunha distinta, bloco econômico, inerente ao movimento de intensificação da internacionalização das relações de produção do interregno atual, e chegou a uma configuração próxima do mercado comum e de liberdades econômicas pensado em sua gestação do pós-guerra.

A inflexão que marcou a trajetória comunitária veio como resposta às transformações internacionais. A opção foi pelo aprofundamento normativo e institucional. Esse incremento 
ocorreu via uma organização internacional que abrigou as iniciativas esparsas de cooperação em diversas áreas sob uma mesma condução política e respaldou a consolidação do mercado comum, objetivo perseguido desde os primórdios da integração. A forma jurídica decorrente vem respaldar a arquitetura econômica norteadora do processo de relançamento da integração, com todas as particularidades de seu ordenamento legal. A forma jurídica acompanhou as transformações comunitárias, no sentido de legitimar e legalizar sua economia política regente. Portanto, o aumento da normatividade e da institucionalidade não gerou, todavia, maior coesão social entre os países, mas, ao contrário, é por meio delas que se descontrói as garantias jurídicas e conquistas sociais, descontruindo o modo de regulação de bem-estar social. A contradição não é fortuita, mas é fruto inerente do processo de internacionalização do direito que envolveu o erguimento do direito da União Europeia.

Desses impactos destacam-se incomodamente dois: a deterioração social, mediante a retirada de direitos e garantias dos cidadãos via acordos internacionais, mecanismos formais e tribunais comunitários, e o fortalecimento de uma dinâmica autoritária, antidemocrática, que ocorre à revelia das populações abarcadas.

Desse modo, o desmonte do modo de regulação de bem-estar social, uma das conquistas da era fordista, é erodido pela intensificação da integração regional, em direção à transferência de competências econômicas soberanas para a organização internacional. Criou-se um espaço econômico comum, que transcendesse a luta de classes, paralelo às economias nacionais, no qual os capitais nacionais e internacionais se encontravam livres de barreiras tarifárias e controles políticos. Esse movimento fortaleceu os foros e as regras regionais em detrimento do controle governamental, tornando os Estados ainda mais vulneráveis às oscilações do mercado, sobretudo no tocante às searas econômica e social.

Por fim, a compreensão da forma jurídica comunitária aclara as ilusões e os aparentes paradoxos contidos na conjunção da prática com a teoria dominante, dinâmica que esconde o real caráter do direito da União Europeia, escancarando a deterioração democrática e social surgidas no bloco em meio ao novo padrão de desenvolvimento do capitalismo. Nesse cenário de internacionalização do direito, a aplicação do direito da integração atua, portanto, na contramão do que se gaba, ou seja, contribuindo para o esgarçamento do tecido social e para o reforço das assimetrias. Apreender as razões e os contornos do fenômeno social, notadamente da União Europeia, é ir além da escrita e desenrolar os fios que tecem a forma. É ampliar o horizonte de análise para a totalidade concreta que cerca a abstração normativa. É considerar os aspectos 


\section{UDIREITO}

O DIREITO DA UNIÃO EUROPEIA E A DETERIORAÇÃO DEMOCRÁTICA E SOCIAL

LUIZ FELIPE BRANDÃO OSÓRIO

político-econômicos que cercam e embasam o arcabouço normativo. Nesse diapasão, observa-se a imprescindibilidade do estudo com ênfase na forma para aclarar o conteúdo nela condensado.

\section{REFERÊNCIAS}

AGLIETTÁ, Michel. Zona do Euro: qual o futuro? Tradução de Christian Perret Gentil. São Paulo: Ideias \& Letras, 2013.

ALDECOA LUZÁRRAGA, Francisco; GUINEA LLORENTE, Mercedes. La Europa que viene: El Tratado de Lisboa. Versiones consolidadas del Tratado de la Unión Europea y del Tratado de funcionamento de la Unión Europea. Madri: Marcial Pons, 2008.

ALTVATER, Elmar. A Crise Econômica Internacional e o Desenvolvimento Sustentável. Brasil e América Latina. Videoaula 12- A Integração Europeia, a regionalização no mundo e a crise. Disciplina Tópicos Especiais do CAPES/Programa de Pós-Graduação em Políticas Públicas e Formação Humana da Universidade do Estado do Rio de Janeiro. Rio de Janeiro: Arissas Multimídia, 2013.

ANDERSON, Perry. El nuevo viejo mundo. Madri: Ediciones Akal S.A., 2012.

AVELÃS NUNES, António José. Crise do Capitalismo, Crise da Europa. Parte I. Revista Jurídica Unicuritiba. Vol 4. N³3, Curitiba, 2014a, p. 5-22.

AVELÃS NUNES. Crise do Capitalismo, Crise da Europa. Parte II. Revista Jurídica Unicuritiba. Vol. 1. $n^{\circ}$ 34, Curitiba, 2014b, p. 5-24.

BELLAMY, Richard; CASTIGLIONE, Dario. O Déficit Democrático da Europa e o Problema Constitucional. IN: COSTA, Piero; ZOLO, Danilo. O Estado de Direito: história, teoria, crítica. São Paulo: Martins Fontes, 2006, p. 611-648.

BOYER, Robert. A Teoria da Regulação. Uma análise crítica. Tradução Renée Barata Zicman. São Paulo: Nobel, 1990.

DINH, Nguyen Quoc, PELLET, Alain e DAILLIER, Patrick. Direito Internacional Público (2 ed.). Lisboa, Calouste Gulbenkian, 2003.

DOUZINAS, Costas. Class bites back in European Union Euro. Disponível em:

$<$ http://criticallegalthinking.com/2009/04/03/class-bites-back-in-the-european-union/>. Acesso em: 15 jan. 2013.

DOUZINAS, Costas. The End of Politics (2): Europe. Disponível em:

<http://criticallegalthinking.com/2010/11/23/the-end-of-politics-2-europe/>. Acesso em: 15 maio 2014

HIRSCH, Joachim; ROTH, Roland. Das neue Gesicht des Kapitalismus: vom Fordismus zum Postfordismus. Hamburg: VSA, 1986. 
HIRSCH, Joachim. Fordism and Post-Fordism: the present social crisis and its consequences. IN: BONEFELD, Werner; HOLOWAY, John. Post-Fordism \& social form. A Marxist debate on the PostFordist State. London: Macmillan Academic and Professional LTD, 1991, p. 8-34.

HIRSCH, Joachim. Der nationale Wettbewerbsstaat. Staat, Demokratie und Politik im globalen Kapitalismus. Berlin: Edition ID-Archiv, 1995.

HIRSCH, Joachim. Teoria Materialista do Estado: processos de transformação do sistema capitalista de Estados. Rio de Janeiro: Editora Revan, 2010.

MANGAS MARTÍN, A.; LIÑÁN NOGUERAS, D. J. Instituciones y Derecho de la Unión Europea. 6. ed. Madrid: Tecnos, 2005.

MARX, Karl. O Capital. Crítica da Economia Política. Livro III: o processo global da produção capitalista. Tradução de Rubens Enderle. Edição de Friedrich Engels. São Paulo: Boitempo, 2017.

MASCARO, Alysson Leandro. Estado e Forma Política. São Paulo: Boitempo Editorial, 2013.

MIÉVILLE, China. Between equal rights: a Marxist theory of international law. Leiden, Boston: Brill, 2006.

NAVES, Márcio Bilharinho. Prefácio ao livro O Socialismo Jurídico. IN: ENGELS, Friedrich e KAUTSKY, Karl. O Socialismo Jurídico. São Paulo: Boitempo, 2012, pp. 9-16.

OSORIO, Luiz Felipe. Um estudo crítico da União Europeia: contradições de seu desenvolvimento institucional e normativo. 2015. Tese (Programa de Pós-Graduação em Economia Política Internacional) - UFRJ, Rio de Janeiro, 2015.

OSORIO, Luiz Felipe Brandão. Forma política e integração regional via União Europeia. Brazilian Journal of Internacional Relations. UNESP-Marília, 2017, Vol. 6, p. 280-305.

PACHUKANIS, Evguiéni. Teoria Geral do Direito e Marxismo. São Paulo: Boitempo, 2017.

PANITCH, Leo; GINDIN, Sam e AQUANNO, Scott. "American Empire and the relative autonomy of European capitalism”. Competition \& Change. Vol. 19 (2), 2015, p. 113-128.

PEREIRA, Luiz Ismael; ERKERT, Jonathan Erik von. Uma radiografia marxista do Estado e do direito. Margem Esquerda. № 26. São Paulo: Boitempo, $1^{\circ}$ semestre de 2016, p. 147-150.

PISARELLO. Gerardo. Un Largo Termidor. La ofensiva del constitucionalismo antidemocrático. Madri: Editorial Trotta, 2011.

\section{COMO FAZER A REFERÊNCIA DO ARTIGO (ABNT):}

OSÓRIO, Luiz Felipe Brandão. O Direito da União Europeia e a deterioração democrática e social. Revista Eletrônica do Curso de Direito da UFSM, Santa Maria, RS, v. 13, n. 1, p. 265-318, abr. 2018. ISSN 1981-3694. Disponível em: < https://periodicos.ufsm.br/revistadireito/article/view/29158 >. Acesso em: dia mês. ano. doi: http://dx.doi.org/10.5902/1981369429158 . 